\title{
BULK GROWTH AND PHYSICAL PROPERTIES OF NONLINEAR OPTICAL MATERIAL: THIOUREA SULPHAMIC ACID CRYSTAL
}

\author{
N. Senthilvelan ${ }^{1, *}$, G. Rajarajan', S. Sivakumar ${ }^{3}$, J. Elanchezhiyan' \\ and A. Jegatheesan ${ }^{4}$ \\ ${ }^{1}$ Department of Physics, Arignar Anna Government Arts College, Attur - 636 121, India \\ ${ }^{2}$ Department Physics, Vidhya Mandhir Institute of Technology, Erode - 638 052, India \\ ${ }^{3}$ Department of Physics, Government Arts College, Salem - 636 007, India \\ ${ }^{4}$ Department of Physics, Pavai College of Technology, Namakkal - 637 018, India \\ *E-Mail: nsenthilvelan2013@gmail.com
}

\begin{abstract}
Nonlinear optical crystals of Thiourea Sulphamic Acid (TS) crystals have been successfully grown by employing slow evaporation technique. The grown crystals were characterized using powder X-Ray diffraction analysis for the crystal system and lattice parameter values. The vibrational behavior was analyzed by means of FTIR spectral technique. UV-Vis-NIR spectral study revealed that the grown crystals have a wide transmission window in the entire visible region with the lower cutoff wavelength $237 \mathrm{~nm}$. The Vicker's microhardness test was carried out on the grown crystals to study the mechanical strength therein, the Vicker's hardness number (Hv) were calculated. The grown crystals of thiourea sulphamic were subjected to thermal studies to confirm that the decomposition of crystals takes place in three different stages making them suitable for device fabrication for frequency conversion applications. Surface Morphology of the grown crystal was confirmed through SEM analysis. The second harmonic generation of the crystals was confirmed by employing Kurtz powder technique to ascertain the nonlinear optical property.
\end{abstract}

Keywords: Thiourea, Sulphamic Acid, XRD, FTIR, UV-Visible, Thermal, SHG.

(C) RASĀYAN. All rights reserved

\section{INTRODUCTION}

Nonlinear optics plays a central role in the developing era of photonics. Photonics includes the application of photons for information and image processing. Non-Linear optical crystal is an important part in research arena due to their hands-on applications such as optical computing, optical information processing, optical communication, medical diagnostics, laser remote sensing, optical disk data storage, laser fusion reactions, color display, etc. Nonlinear optical processes have applications in vital functions such as frequency conversion and optical switching. ${ }^{1}$ Organic crystals can have very large nonlinear susceptibilities relative to inorganic crystals, but exhibit low damage threshold and poor processibility. ${ }^{2-6}$ For overcoming these difficulties, the search for new materials with high optical nonlinearities is an everlasting process.

In semiorganic materials, the organic ligand is ionically bonded with the inorganic host. Organic nonlinear materials are attracting a great deal of attention, as they have large optical susceptibilities, inherent ultra-fast response times and high optical thresholds for laser power as compared with inorganic materials. ${ }^{7}$ Sulphamic acid is a classical inorganic compound and an important industrial chemical with a yearly production of several kilotons. ${ }^{8}$ Sulphamic Acid is used to Descaler, Detergent \& Corrosion Remover, Removing additional cement on tiles, efflorescence and other mineral deposits etc. Industrial uses of thiourea include the production of flame retardant resins and vulcanization accelerators. Thiourea is used as an auxiliary agent in diazo paper, light-sensitive photocopy paper and almost all other types of copy paper. It is also used to tone silver-gelatin photographic prints. The main application of thiourea is in 
textile processing. Urea $\left(\mathrm{N}_{2} \mathrm{H}_{4} \mathrm{CO}\right)$ and Thiourea $\left(\mathrm{N}_{2} \mathrm{H}_{4} \mathrm{CS}\right)$ are simple organic molecules with immense dipole moment and have the ability to form a large scale network of hydrogen bonds. Dopant is added to occupy the interstitial positions in the lattice and in turn this may lead to distinctive changes in the physical properties of thiourea sulphamic acid. ${ }^{9-12}$ Due to its interesting property, in the present investigation, an attempt made to grow thiourea sulphamic acid crystals. The primary aim of the article is to investigate the influence of thiourea on the optical and thermal properties of thiourea sulphamic acid crystals.

\section{EXPERIMENTAL}

Synthesis and Solubility of Thiourea Sulphamic Acid Crystals

TS was synthesized from Thiourea Sulphamic Acid taken in the molar ratio of 1:1 by slow evaporation technique. The reactants were thoroughly dissolved in double distilled water and stirred well using a temperature controlled magnetic stirrer to yield a homogeneous mixture of the solution. Then the solution was allowed to evaporate at room temperature, which results in the yield of white crystalline salt of TS due to super saturation followed by nucleation:

$$
\mathrm{H}_{2} \mathrm{~N}-\mathrm{CS}-\mathrm{NH}_{2}+\mathrm{HO}-\mathrm{SO}_{2}-\mathrm{NH}_{2} \rightarrow\left(\mathrm{H}_{2} \mathrm{~N}-\mathrm{CS}-\mathrm{NH}_{3}\right) \mathrm{SO}_{3}-\mathrm{NH}_{2}
$$

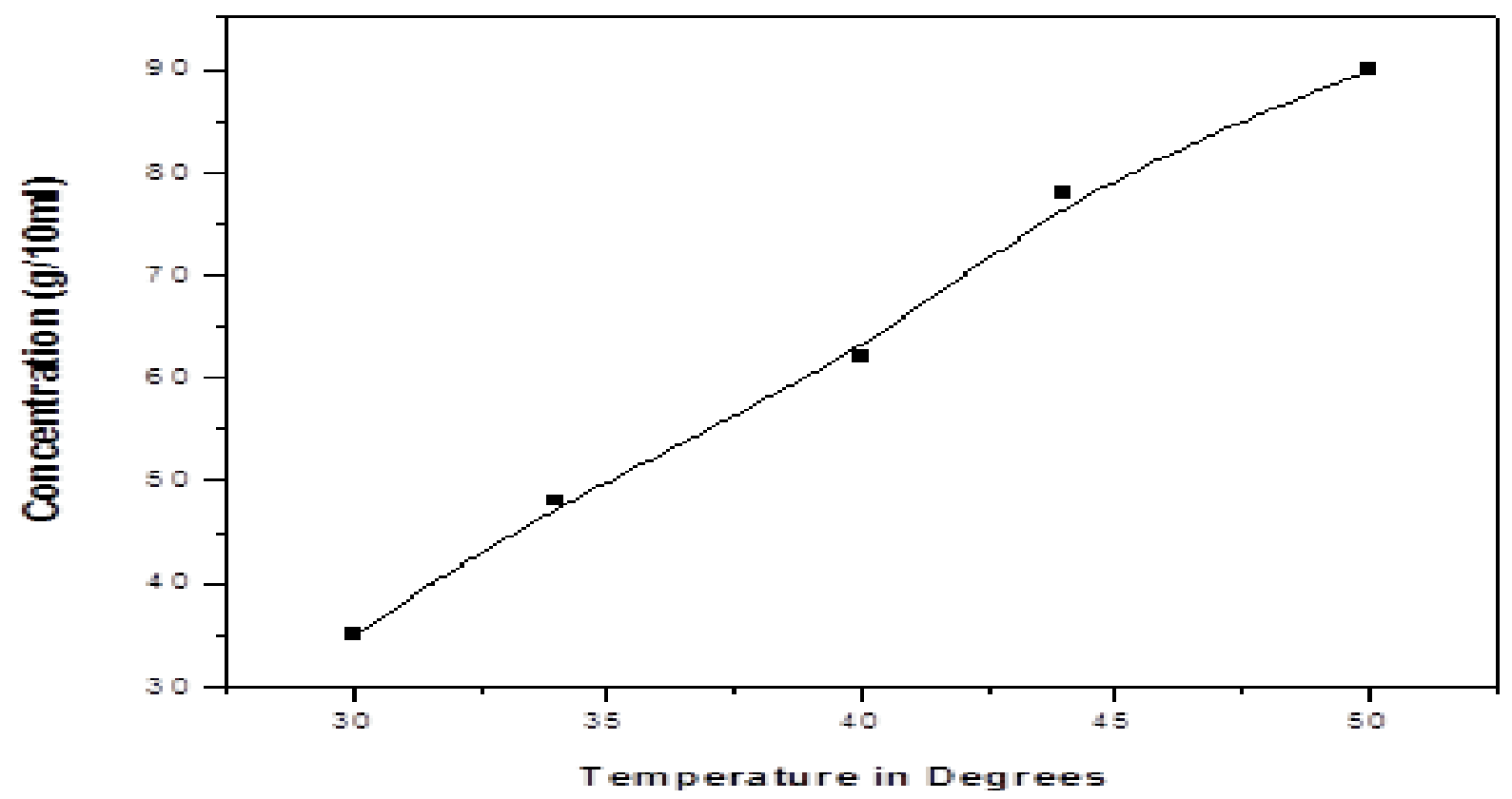

Fig.-1: Solubility Curves of TS Crystal

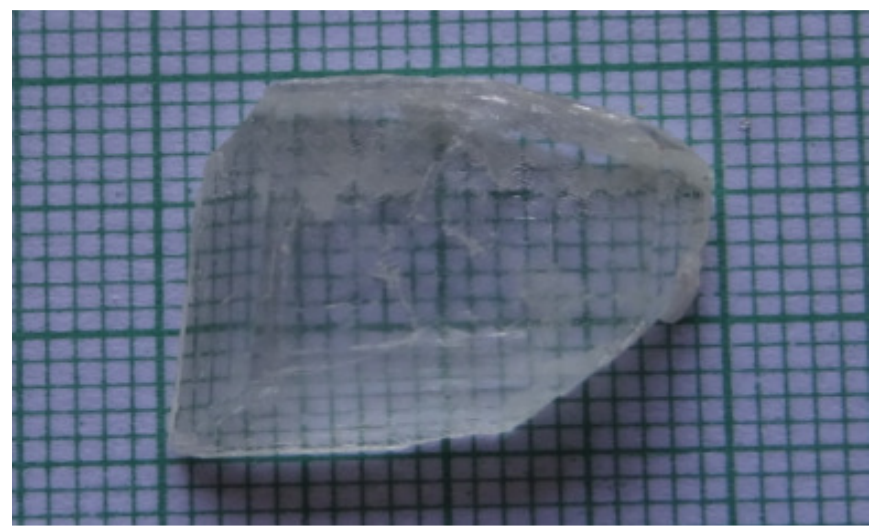

Fig.-2: Image of Grown TS Crystal 
The seed crystals were harvested from the solution after eight days and a suitable seed was selected. The selected seed was suspended in the freshly prepared solution. After a period of 15 days, optically transparent defect-free crystals were obtained from the mother solution. Fig.-1 shows the Solubility curves of TS. Fig.-2 shows the as-grown crystal of TS with an optimized solution pH value of 3.2.

\section{Characterization Studies}

The grown pure and doped TS single crystals have been subjected to numerous characterization studies. The Rigaku ultima III X-Ray diffractometer with $\mathrm{CuK \alpha} \alpha_{1}(\lambda=1.5406 \AA)$ was used to estimate the cell parameters. The Fourier transform infrared spectroscopy (FTIR) spectrum was recorded using a Perkin Elmer make model Spectrum Rx1 spectrophotometer using KBr pellet technique in the region 4000-400 $\mathrm{cm}^{-1}$. The UV-vis absorption spectrum was studied in the range 190- $1100 \mathrm{~nm}$ by Perkin Elmer make model Lambada 35 UV-Vis-NIR spectrophotometer in the range 190-1100 nm. Microhardness study of the crystals was carried out using MUTUTOYOM112 microhardness tester fitted with a diamond pyramidal indenter. The thermal gravimetric analysis (TGA)/differential scanning calorimetry (DSC) studies showed the thermal properties of grown crystal carried using TA instruments (model: Q600 SDT and Q20 DSC thermal analyser) are carried out at the room temperature to $700^{\circ} \mathrm{C}$ at a heating rate of $10^{\circ} \mathrm{C}$ min in the nitrogen atmosphere. Nonlinear optical property of the crystal was confirmed using the Kurtz and Perry powder technique by passing the fundamental beam of Q-switched, mode-locked Nd:YAG laser operating at $1.06 \mu \mathrm{m}$ and pulse width of $8 \mathrm{~ns}$ laser pulse with a spot radius of $1 \mathrm{~mm}$.

\section{Powder X-Ray Diffraction}

\section{RESULTS AND DISCUSSION}

The structural properties of single crystals of TS have been studied by X-Ray Powder diffraction technique. The X-Ray diffraction studies were carried out using Rigaku ultima III X-Ray diffractometer with $\mathrm{CuK \alpha} \alpha_{1}(\lambda=1.5406 \AA)$ radiation. The powdered samples were scanned over the range $10^{\circ}-80^{\circ}$ at a rate of $1^{\circ}$ per minute. From the powdered X-ray data, the various planes of reflections were indexed using XRDA 3.1 program and the lattice parameters were evaluated.

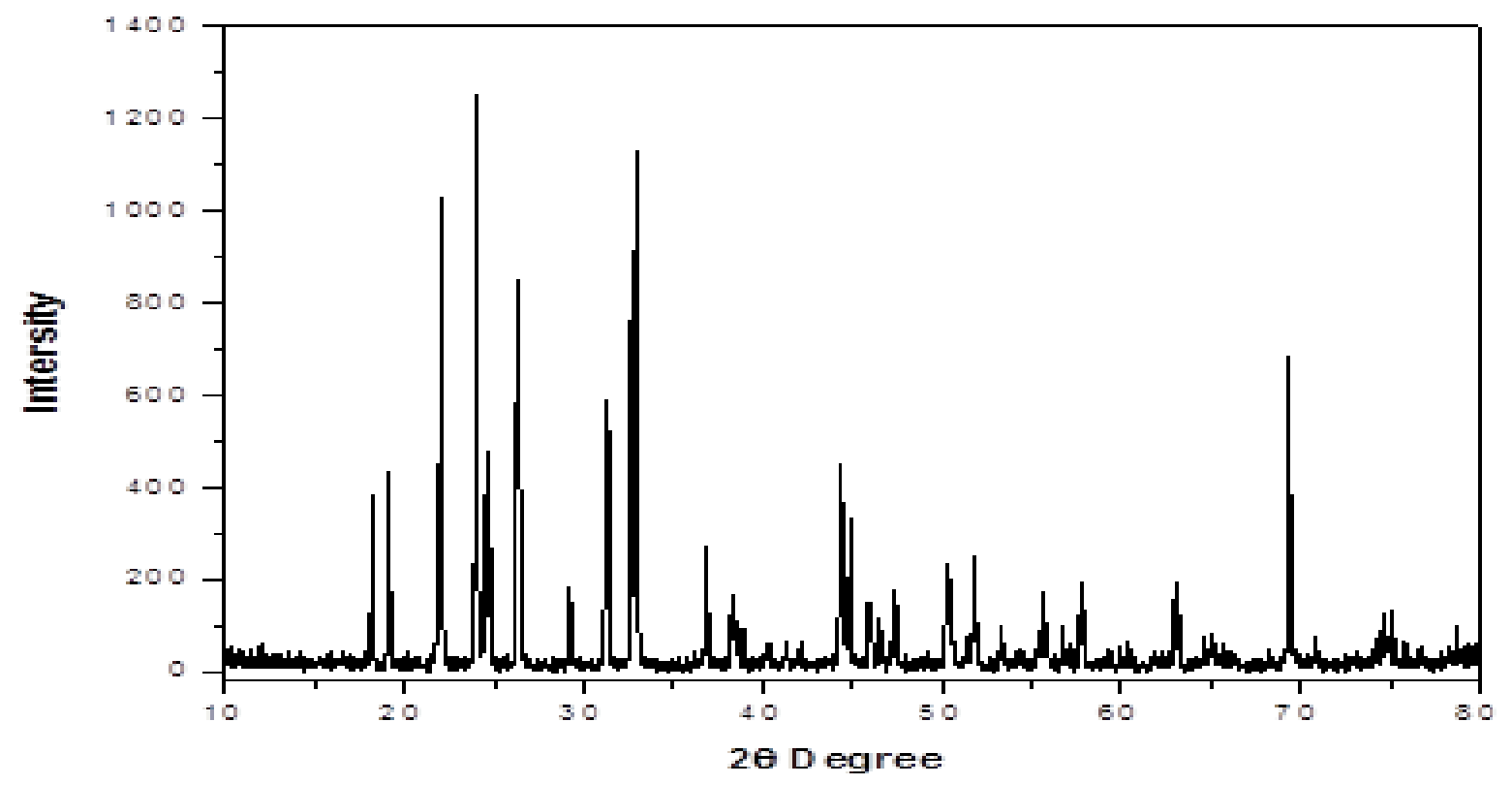

Fig.-3: The XRD Pattern of TS Crystal

The lattice parameters are $\mathrm{a}(\AA)=25.077, \mathrm{~b}(\AA)=10.092$ and $\mathrm{c}(\AA)=9.288$ and the unit cell volume is $2153.9 \mathrm{~A}^{3}$. TS belongs to the primitive Triclinic system, The Powder X-ray diffraction pattern is shown in Fig.-3. The results are good agreement with the reported values. ${ }^{13}$ 


\section{FTIR Measurements}

The FTIR spectrum of TS is shown in Fig.-4 and the vibrational modes and frequencies. The frequency observed at 3949 and $3829 \mathrm{~cm}^{-1}$ is due to the intermolecular hydrogen bonding as well as asymmetric $\mathrm{NH}_{2}$ stretching vibration present in the compound.

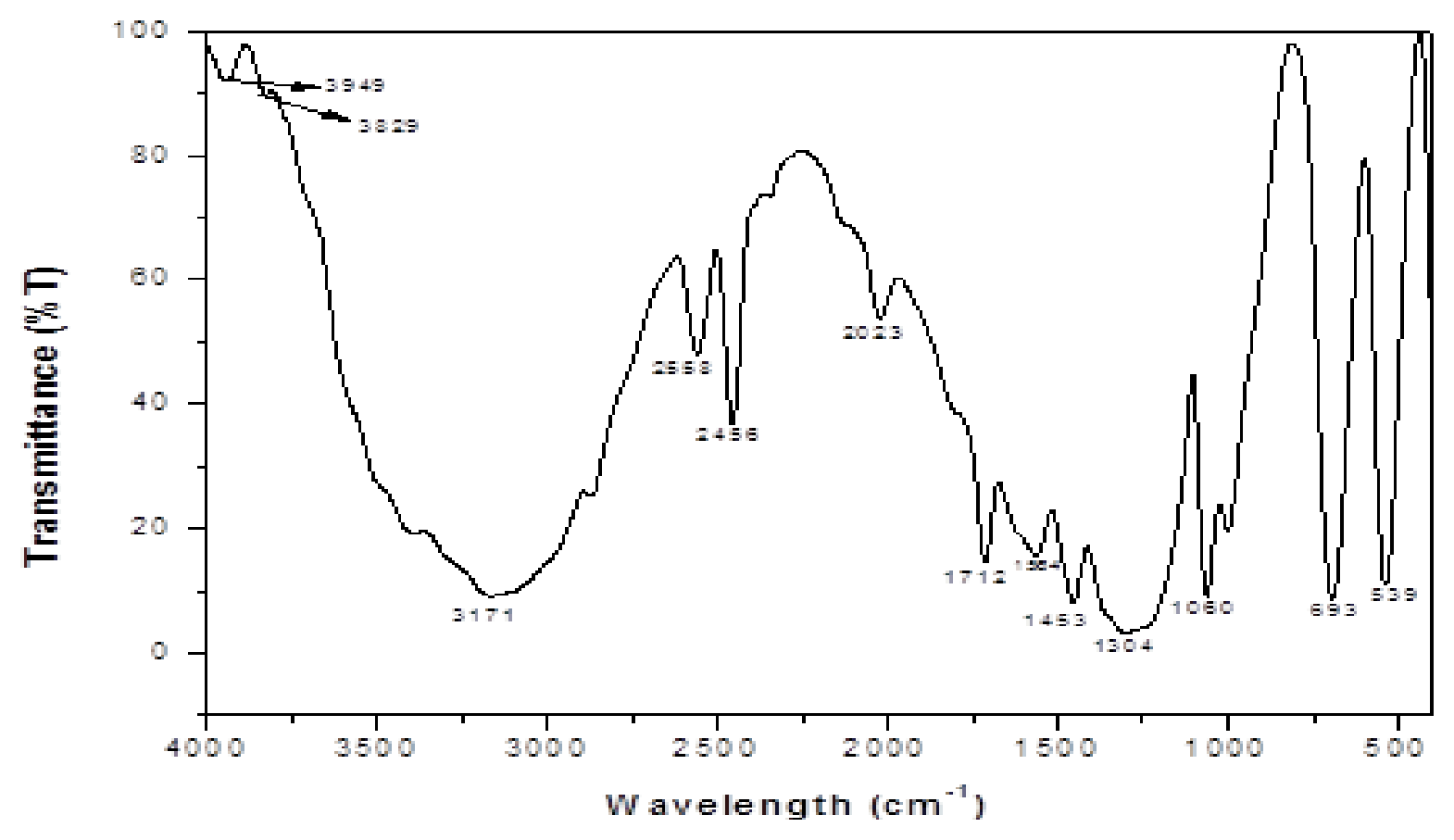

Fig.-4: FTIR Spectrum of TS Crystal

The absorption frequency at 3171,2558 and $2456 \mathrm{~cm}^{-1}$ is due to the symmetric $\mathrm{O}-\mathrm{H}$ stretching vibration mode. The absorption frequency at 2023 and $1712 \mathrm{~cm}^{-1}$ is due to the $\mathrm{C}-\mathrm{N}$ stretching present in the aromatic nucleus. The frequency at $1564 \mathrm{~cm}^{-1}$ which appear in $\mathrm{SO}_{3}{ }^{-}$deformation vibration. The absorption frequency at 1453 and $1304 \mathrm{~cm}^{-1}$ is due to $\mathrm{O}-\mathrm{H}$ bending vibration. The absorption frequencies at 1060,1000 and $693 \mathrm{~cm}^{-1}$ are due to the $\mathrm{C}-\mathrm{S}$ stretching vibration mode. The peaks observed at $539 \mathrm{~cm}^{-1}$ is $\mathrm{N}-\mathrm{S}$ stretching vibration mode. ${ }^{14-17}$

\section{UV-Vis Spectrum}

The UV-vis transmittance and absorption spectra Fig.-5 was recorded using Perkin Elmer make model Lambada 35 UV-Vis-NIR spectrophotometer in the range 190-1100 $\mathrm{nm}$. Optically clear single crystal was used for this study and the crystal is transparent and there is no absorption in the entire region. The lower cut-off wavelength is $237 \mathrm{~nm}$. As there is no absorption in the visible and near infrared region it can be used as a potential material for frequency doubling. ${ }^{18}$

\section{Vicker's Hardness Test}

Hardness is one of the important mechanical properties of the solid material. It can be used as a suitable measure of the plastic properties and strength of the material. Microhardness analysis was carried out using Vickers Microhardness tester fitted with a diamond indentor. The well-polished TS crystal was placed on the platform on the Vicker's Microhardness tester and loads of different magnitude (25-100 gm) were applied over a fixed interval of time. ${ }^{19}$ The indentation time was kept at $5 \mathrm{sec}$. for all the loads. The Vicker's hardness number of the grown crystals was calculated using the relation:

$$
H_{v}=\frac{1.8544 P}{d^{2}} \mathrm{Kg} / \mathrm{mm}^{2}
$$


RASĀYAN J. Chem.

Vol. 10 | No. 1 |245 -253 | January - March | 2017

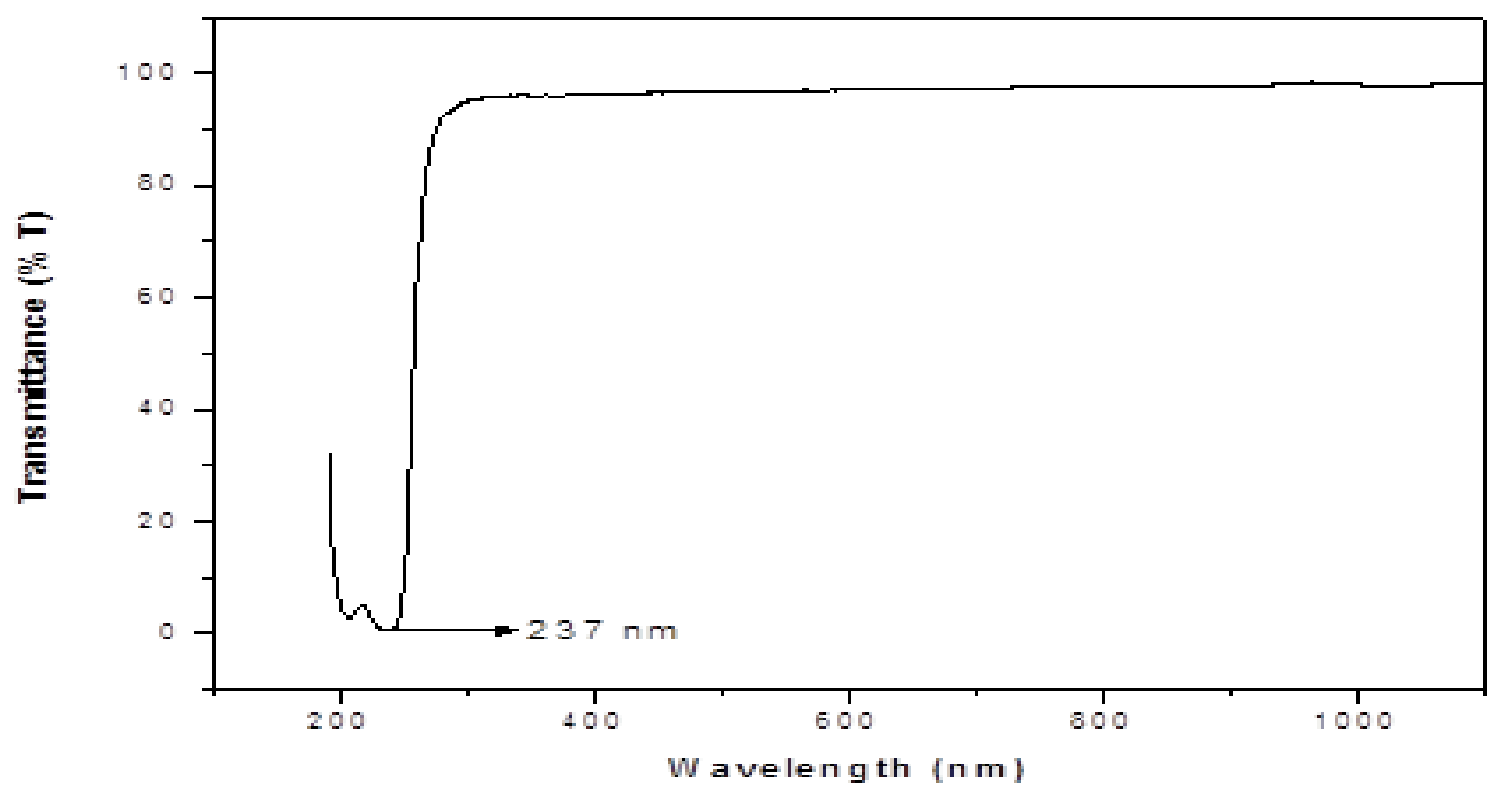

Fig.-5: UV-Vis Spectrum of TS Crystal

$\mathrm{P}$ is the applied load in $\mathrm{kg}, \mathrm{d}$ is the average diagonal length in $\mathrm{mm}$ of the indentation impression. The relation between hardness number $\left(\mathrm{H}_{\mathrm{v}}\right)$ and load $(\mathrm{P})$ for TS is shown in Fig.6. The hardness increases gradually with the increase of load and above $100 \mathrm{~g}$ cracks develops on the smooth surface of the crystal due to release of the internal stresses generated locally by indentation.

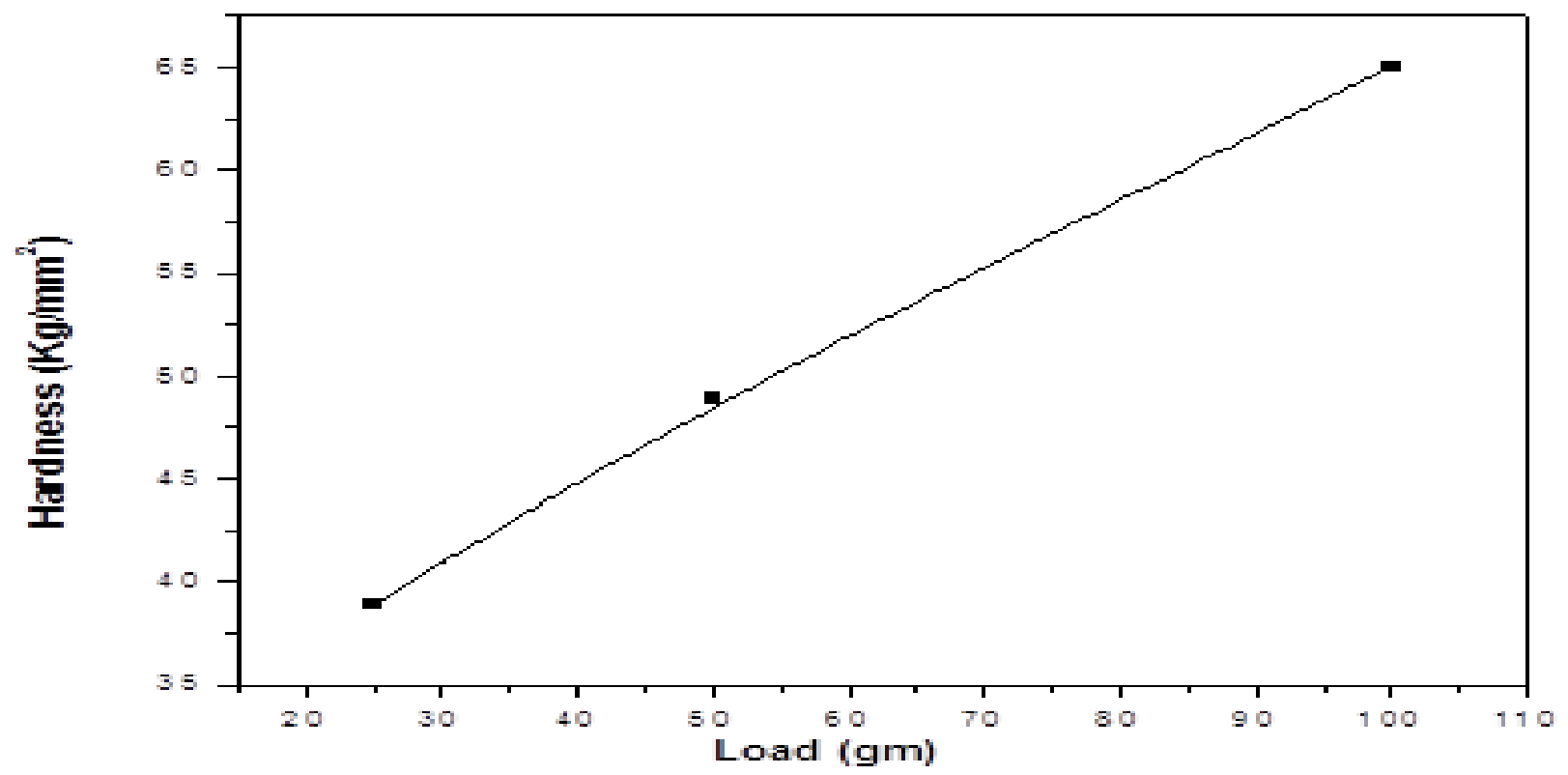

Fig.-6: Vickers Hardness Vs Load for TS Crystal

\section{Scanning Electron Microscopy Studies (SEM)}

Chemical analysis and morphological studies were carried out using scanning electron microscopy (SEM model JSM 840A). Fig.-7 illustrates the SEM image of the crystal. It shows some darker and brighter uneven areas. This might be due to solvent inclusions, which is most commonly observed in solution growth. Interesting features of surface morphologies are observed in SEM, actually, exhibits stepped 
RASĀYAN J. Chem.

Vol. 10 | No. 1 |245 -253 | January - March | 2017

structure. ${ }^{20-21}$ Variations in step directions and the appearance of wider steps could be attributed to the general roughness / grain boundary.

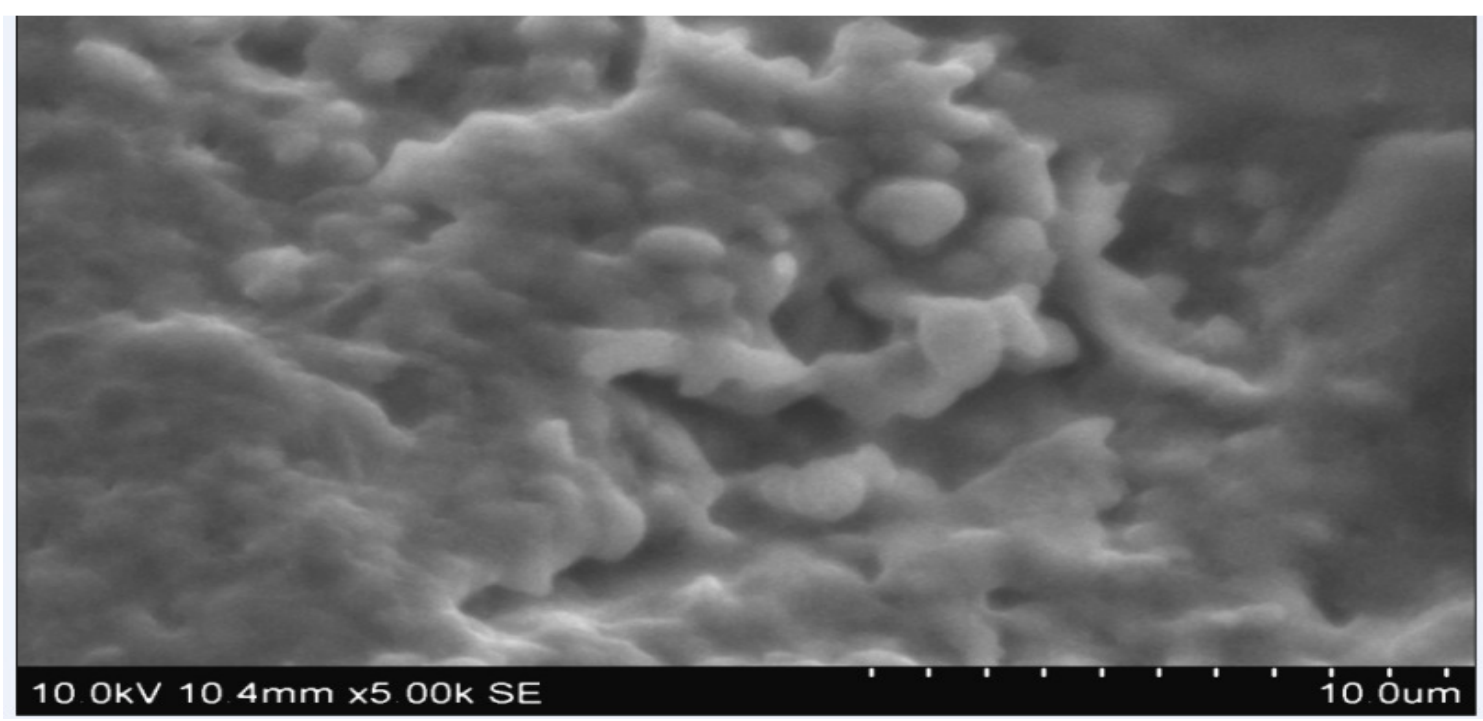

\section{Thermal Studies}

Fig.-7: SEM Image of TS Crystal

\section{TGA Analysis}

The TGA response curves for the powder sample TS is shown in Fig.-8. In the TGA trace, there is a major weight loss of $100 \%$ starting at about $10-15^{\circ} \mathrm{C}$. It is due to the decomposition and volatilization of the compound. The next weight loss occurs between 17 and $22^{\circ} \mathrm{C}$ shows that the decomposition is almost complete. The other endotherms or exotherms observed coincides exactly with the decomposition observed in TGA trace. ${ }^{22}$ It is concluded that the TS crystal is suitable for NLO applications up to $39^{\circ} \mathrm{C}$.

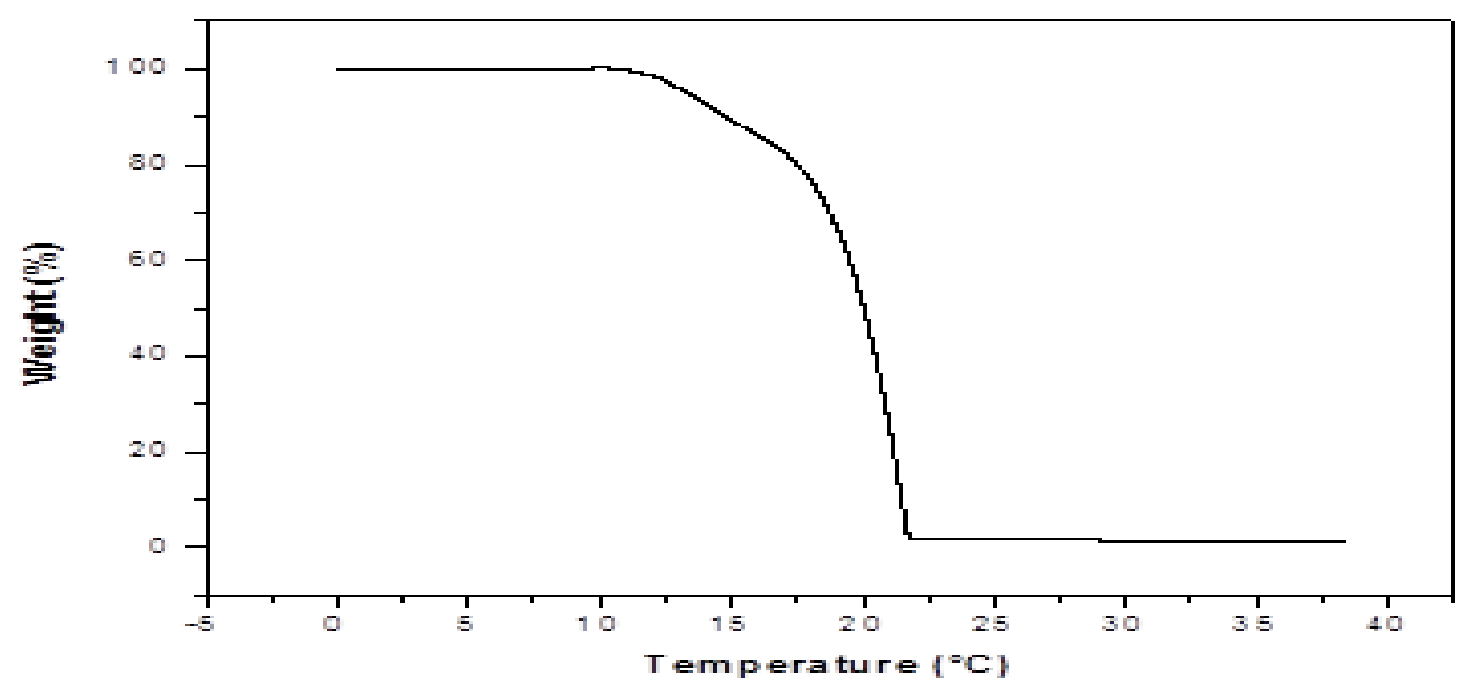

\section{DSC Analysis}

Fig.-8: TGA Curve of TS Crystal

The DSC curve shown in Fig. -9 shows that there is no phase transition up to $200^{\circ} \mathrm{C}$. There is second weight loss at a temperature of $242^{\circ} \mathrm{C}$ and after that one distinct anomaly of heat was observed at $290^{\circ} \mathrm{C}$. The first endothermic curve corresponds to a loss of water. The thermogram also shows the decomposition temperature at $290^{\circ} \mathrm{C}$. The reduction in decomposition value of doped TS crystal as compared to pure TS may be attributed to decrease in bond energy caused by the addition of a dopant. ${ }^{23}$ 
RASĀYAN J. Chem.

Vol. 10 | No. 1 | 245 -253 | January - March | 2017

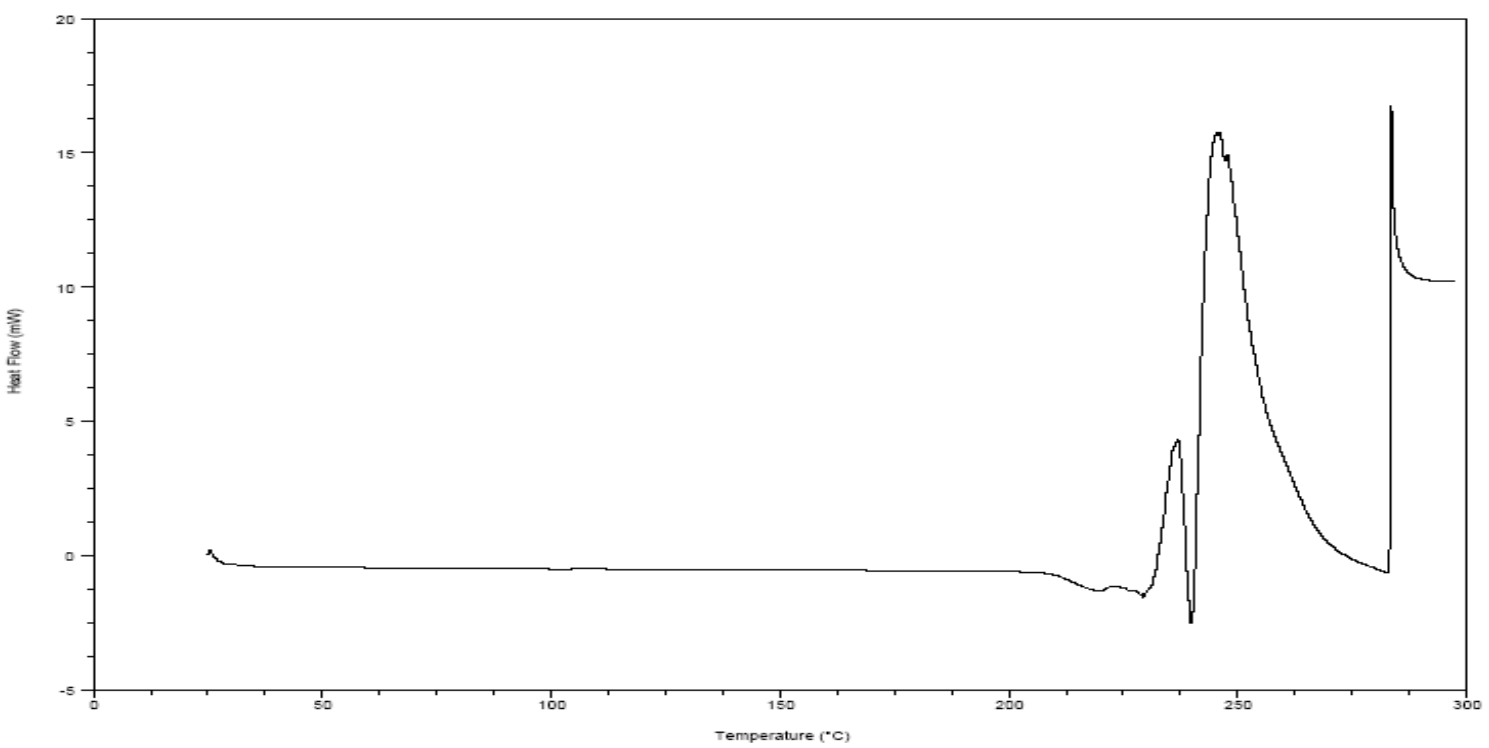

Fig.-9: DSC Curve of TS Crystal

\section{Dielectric Studies}

The dielectric constant of the TS crystals was studied at different temperatures using HIOKI 3532 LCR HITESTER. Fig.10 shows the plot of dielectric constant $\left(\varepsilon_{\mathrm{r}}\right)$ vs log frequency. The dielectric constant has high values in the lower frequency region and then decreases with the applied frequency. The very high value of $\varepsilon_{\mathrm{r}}$ at low frequencies may be due to the presence of all the four polarizations namely, space charge, orientation, electronic and ionic polarization and its low value at higher frequencies may be due to the loss of significance of these polarizations gradually. ${ }^{24-27}$ From the plot, it is also observed that dielectric constant decreases with increasing frequency, attributed to space charge polarization near the grain boundary interfaces, which depends on the purity and perfection of the sample.

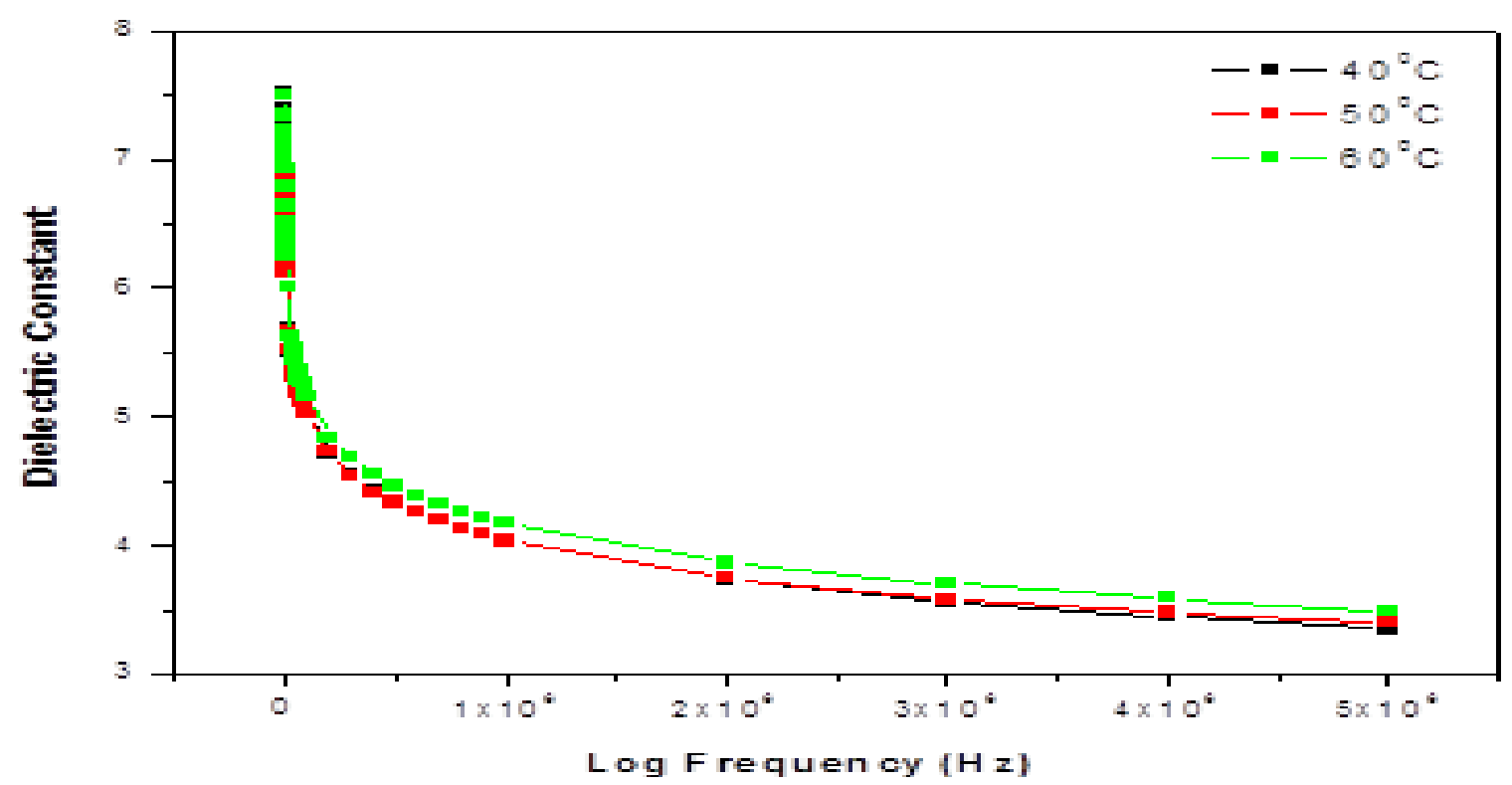

Fig.-10: Variation of Dielectric Constant with Frequency for TS Crystal

\section{Second Harmonic Generation NLO Study}

In order to confirm the NLO behavior of this material, the powder sample was subjected to Kurtz and Perry technique. ${ }^{28}$ A fundamental beam of wavelength $1064 \mathrm{~nm}$ with a pulse duration of $10 \mathrm{~ns}$ and the 
frequency repetition of $10 \mathrm{~Hz}$ from Q-switched Nd:YAG laser has been used as a source and passed through the powder sample of particle size $1.2 \mathrm{~nm}$ for second harmonic generation efficiency (SHG) study. Pulse energy and pulse width are maintained as $321 \mathrm{~mJ} \mathrm{~s}^{-1}$ and $8 \mathrm{~ns}$ respectively.

The $532 \mathrm{~nm}$ radiation was collected by a monochromator, after separating the $1064 \mathrm{~nm}$ pump beam with an infra-red blocking filter. The second harmonic radiation generated by the randomly oriented microcrystals was focused by a lens and detected by a photomultiplier tube. The second harmonic generation is confirmed by the emission of green radiation from the crystal. The second harmonic out signal was $98 \mathrm{mV}$ and was obtained from an input energy $2.149 \mathrm{~mJ} /$ pulse with a pulse width of $8 \mathrm{~ns}$. The second harmonic generation (SHG) of the TS crystal was demonstrated by Kurtz Perry method using Nd: YAG laser and the result confirms that the grown crystal is $140 \%$ as that of KDP.

\section{CONCLUSION}

After careful optimization crystal of TS is successfully grown by slow evaporation technique. X-ray diffraction analysis confirms the improvement in the crystalline quality of grown doped TS crystals. The presence of dopants has slightly retailored the lattice parameters without affecting the basic arrangement of crystals. It is noticed that the dopants thiourea has improved the hardness which shows the importance of doping in the mechanical stability of optical applications. The presence of various functional groups of the molecules was confirmed by FTIR analysis. The thermal analysis shows that there is no phase transformation or vaporization before melting point and stable $29^{\circ} \mathrm{C}$ doped crystals. The Dielctric behavior of the grown crystals were confirmed form the dielectric test. The SHG efficiency of thiourea doped SA was found to be equal to the reference material KDP.

\section{REFERENCES}

1. P. N. Prasad and D. J. Williams, Introduction to Nonlinear Optical Effects in Molecules and Polymers, John-Wiley and Sons Inc, New York, (1991)

2. S. X. Dou, D. Josse, and J. Zyss, J. Opt. Soc. Am. B, 10, 1708 (1993).

3. B. Neelakantaprasad, G. Rajarajan, J. Senthilkumar, D. Marimuthu, C. Sadeeshkumar, B. Ravi and A. Jegatheesan, Rasayan Journal of Chemistry, 7, 190 (2014)

4. G. Knopfle, R. Schlesser, R. Ducret and Gunter, Nonlinear Opt., 9, 143 (1995).

5. B. Neelakantaprasad, G. Rajarajan, D. Marimuthu, J. Senthilkumar, A. Jegatheesan, and B. Ravi, Rasayan Journal of Chemistry, 7, 143 (2014)

6. B. Neelakantaprasad, G. Rajarajan, T. Jayanalina, D. Marimuthu, J. Senthilkumar, C. Sadeeshkumar and A. Jegatheesan, Rasayan Journal of Chemistry, 7, 269 (2014)

7. N. Senthilvelan, G. Rajarajan and S. Sivakumar, International Journal of ChemTech Research, 6, $5692(2014)$

8. S. J. Hickling and R. J. Wooley, Chem. Phys. Lett., 166, 43 (1990)

9. B. Ravi, A. Jegatheesan, B. Neelakandaprasad, C. Sadeeshkumar and G.Rajarajan, Rasayan Journal of Chemistry, 7, 287 (2014)

10. P. Selvarajan, J. Glorium Arulraj, S. Perumal, Physica B, 405, 738 (2010)

11. K.D. Parikh, D.J. Dave, B.B. Parekh, M.J. Joshi, Bull. Mater. Sci., 30, 434 (2007)

12. T. Prasanyaa, M. Haris, V. Mathivanan, M. Senthilkumar, T. Mahalingam, V. Jayaramakrishnan, Mat. Phy. and Chem., 1, 6 (2014)

13. B. Kannan, P. R. Seshadri, K. Ilangovan and P. Murugakoothan, Indian Journal of Sci. and. Tech, 6, 7 (2013)

14. R.M. Silverstein, C.G. Bassler and T.C. Morril, in: Spectroscopic identification of organic compounds, $5^{\text {th }}$ edn (John Wiley \& Sons, New York, 1991) p. 101

15. C. M. Moore, S. Hackman, T. Brennan and S. D. Minteer, J. Membr. Sci. 254, 63 (2005)

16. K. Byrappa, M. A. Kandhaswamy and V. Srinivasan, Cryst. Res. Technol., 34, 143 (1999)

17. Wenwei Ge, Huaijin Zhang, Jiyang Wang, Donggang Ran, Shangquian Sun, Hairui Xia, Junhai Liu, Xiangang Xu, Xiaobo Hu, and Minhua Jiyang. J. Cryst. Growth, 282, 3 (2005).

18. R. Muralidharan, R. Mohankumar, R. Jayavel and P. Ramasamy, J. Crystal Growth, 259, 321 (2003)

THIOUREA SULPHAMIC ACID CRYSTAL 
RASĀYAN J. Chem.

Vol. 10 | No. 1 |245 -253 | January - March | 2017

19. A.J. Varjula, C. Vesta, C.J. Raj, S. Dinakaran, A. Ramanand, S.J. Das, Mater. Lett. 61, 5053 (2007)

20. N.M. Ravindra, R.P. Bharadwaj, K. Sunil Kumar and V.K. Srivastava, Infrared Phys., 21, 369 (1981)

21. A. Jegatheesan, G. Rajarajan, B. Neelakantaprasad and J. Murugan, International Journal of Computer Applications, 53, 15 (2012)

22. W. S. Wang, M. D. Aggarwal, J. Choi, T. Gebre, A. D. Shields, B. G. PennFrazier, Cryst. Growth, 578, 198 (1999).

23. S. Natarajan, K. Ravikumar, S.S.Rajan, Z. Kristallogr. 168, 75 (1984)

24. V. Venkataramanan, S. Maheswaran, J. N. Sherwood and H.L. Bhat, J. Cryst. Growth, 179, 605 (1997)

25. C. P. Smyth, Dielectric Behaviour and Structure (McGraw Hill, New York, 1965)

26. C. Balarew and R. Dehlew, J. Solid State Chem., 55, 1 (1984).

27. L. Misoguti, A. T. Varela, F. D. Nunes, V. S. Bagnato, F. E. A. Melo Mendes J Filho, C. Zilio, Opt. Mater., 6, 147 (1996).

28. S. K. Kurtz and T. T. Perry, J. Appl. Phys., 39, 3798 (1968)

[RJC-1566/2017] 